\title{
Enhancing Problem-Solving Skills and Motivation through Cooperative Learning
}

\begin{abstract}
:
In the present paper, the goal set to assist learners in the process of strategically seeking as well as applying information is given a major consideration in the realm of education. the advantage of raising awareness of problem solving skills and encouraging learners to apply them are two main requirements which go hand in hand to increase performance throughout learning, for we noticed that being informed about some pieces of information does not inevitably necessitate its application but an active involvement into cooperative problem-solving activities fosters higher-order thinking skills namely deductive and inductive types of thinking within cooperative learning environment. Cooperative learning and teaching approach is adopted to increase learners' academic performance in terms of the space left for them to benefit from the positive interdependence which highlights the mutual exchange of learning experiences skills and leads to meaningful and long-term learning. This research reports the importance of taking recourse to cooperative learning as learning and teaching approach which has a generously positive influence on the enhancement of both thinking skills motivation social and collaborative skills.

Keywords: problem solving skills, deduction and induction, motivation, cooperative learning
\end{abstract}

\section{Debache Ahlam}

Faculty of Letters and Languages

Department of Foreign Languages

University of Mentouri

Constantine

\section{Introduction:}

Problem-solving skills are the set of thinking skills, which include deductive and inductive reasoning skills, which are used to make sense of different life events. Hence, the progressive process of manipulating data in an organized and logical way, as well as inducing new ideas from a plethora of information which are collected from a variety of resources are the fundamental. 
requirements for enhancing the quality of both learning and thinking. By active involvement, learners constantly attempt to make sense of the given activity or task through research, and cooperative interaction. Thus, training program was introduced to show learners the significance of understanding and using problem-solving skills within cooperative learning environment as a way to help them see the intertwined link between thinking, practice and cooperative learning. So, learners learn to think deductively and inductively about information, communicate their thoughts and manipulate learning setting and research tools to their benefits, best of all a learning environment, which underlines positive interdependence, reflective thinking, and engagement into activities.

The choice of cooperative learning as a teaching approach is supported by its promising cognitive, motivational and social advantages, which are brought by the mutual exchange of information, alongside with developing an awareness of life events and solving problems. cooperative learning promises every single student to do her share of the task; exploring, thinking, and employing problem-solving strategies to figure out given problems, suggesting possible solutions, and evaluating the effectiveness of the end result (the goal state), a process which is probably demanding yet makes learning more pleasing and meaningful.

\section{2-Thinking Defined}

Trying to define the term thinking is not an easy task which can be fulfilled or taken for granted, contrary to how it may usually sound to a layperson that thinking is any thought that comes into mind. Thinking is given several definitions and perceived differently depending on which angle it is regarded.

According to Moseley (2005:12) the term thinking can be used to describe various mental activities; conscious and semi-conscious such as reflective thinking and daydreaming.

In the realm of psychology, thinking is the mental activity, where data are processed and manipulated to understand and solve problems.

Moreover thinking is viewed to involve a goal to achieve. So, take for example, people who focus their thinking on knowledge obtainment and try to use it proficiently in order to impose their control over their environment . The latter is said to be the goal or a need to meet that is using knowledge to handle daily activities, a process which is identified as thinking.

Thinking is explained as an umbrella term which covers a broad number of mental functions such as memory, problem-solving, decision making, and metacognition.

Given many illustrations of how the word thinking is used, problem solving, memory, decision making, metacognition and reasoning are perceived as different types of thinking, all of which are hypothesized to enhance through 
active an engagement into activities which trigger thinking within a social and cooperative learning environment.

In addition, thinking is the set of mental functions, including problem solving, memorization, decision making, and reasoning, which are consolidated ,and fostered through an optimal learning environment, which primarily emphasizes cooperative learning, research , and thinking being the principal educational requirements, which are called for to meet effectively heterogeneous classrooms' different cognitive and social needs ,as well as, cooperative learning environment is more likely to incubate learners with learning difficulties such as humiliation and lack of motivation.

The hallmark of emphasizing problem solving skills is that learners learn flexibility while handling problem solving activities, that is, they learn to embrace differences among people's ways of perceiving the world and be open to variety of possible alternatives to deal with a given problem.

Moreover, being problem-solvers requires learners not being mere recipients of information but active learners who are striving to act upon knowledge and foster necessary skills in order to facilitate understanding and solution of the given problem solving task successfully (Remembering, comparing and contrasting).

\section{- Memory and Learning}

Working Memory (WM) is described as a multi-store system which is responsible for the short-term storage and the processing of a limited amount of data. Also, working memory coordinates the phonological and spatial items which are indispensable for activities, such as reasoning, visual and spatial processing (Baddely, 1986). Working memory consists of subsystems; the phonological loop, the visuo-special sketch pad, the central executive and finally the episodic buffer.

Likewise, a recent yet more synthesized definition of Working Memory stresses that working memory is an active memory system, which is responsible for temporal holding of different types of information, as well as, the manipulation of multiple items, including visual, and phonological items all of which are stored and processed in the Working Memory for a short period of time, while other cognitive functions like language comprehension, reasoning, problem solving and decision making are taking place (Anderman and Anderman, 2009). In the following, each subsystem contained in Working Memory model is defined and discussed with some details:

-The phonological loop, which is a subsystem in WM, is in charge of holding sounds or phonological information for a limited period of time. These phonological items are stored in accosted code through sub-vocal rehearsal process. The latter is the process that allows the temporary stored items pass to the long term memory LTM. 
-The visuo spatial sketch pad is the subsystem which holds spatial and visual data including pictures, the distance for example between two angles etc..

-Central executive is the working memory's coordinator subsystem, which coordinates the entire system. Note that the central executive is the key mechanism in WM, for it controls all the previously mentioned items including items which are stored in Long Term Memory LTM.

As far as problem solving is concerned, the central executive acts like a decision taker which decides which items, namely audio-visual, phonological, or items which are decades ago, and are relevant (or irrelevant) to the given problem-solving task. Also, the central executive coordinates several cognitive processes including working memory systems, and directs attention towards necessary data stored in long-term memory to tackle a problem (Matlin, 2003).

-Decision Making and Problem Solving

Decision making is another thinking aspect which underlies a set of thinking skills such as problem solving, memorization, reasoning and brain storming.

Given several alternatives, learners switch from being problem -solvers to being decision- makers. In so doing, learners have to consider several alternatives, analyze possible gains and losses, and try new approaches to take an appropriate decision concerning which alternative may be more useful and produces a solution (Brainstorming technique is highly recommended in this phase).

Choosing a particular alternative to unravel an unresolved problem, learners also learn to decide which tools, depending on which learning objective ,are beneficial to problem solving; a process which is importantly influenced by several attributes such as motivation, social interaction and learning styles.

\section{- Problem Solving Skills and Learning}

Problem solving skills are the set of reasoning skills used to reach a solution, understand an environment or explain an event. Deductive reasoning, and inductive reasoning skills both are widely known as thinking skills which are to enhance through active engagement into cooperative problem solving activities and which are both considered the main concerns of this research.

Problem solving skills are of paramount importance during learning, because they are believed to be indispensable for learners to enhance thinking aspects and boost their academic performance.

Through cooperative problem-solving, learners learn and work together to deal with issues, apply problem-solving skills and mutually exchange their findings. Also, within a cooperative learning environment, learners support each other, correct misconceptions, and explain concepts during problemsolving task, thus they develop a deeper sense of belongingness to a group and responsibility for groupmates' learning and success, and boost their motivation to achieve the goal which is shared by all the members of the group. 
The aforementioned learning skills are said to be the $21^{\text {st }}$ century educational requirements, which are particularly emphasized to meet various intellectual as well as social needs, including those, which occur in the workplaces, to name few problem solving and thinking skills, collaborative skills, and selfmotivating skills. This perhaps includes everything which exists or takes place around, and the tools used to represent it in an empirical way (e.g., graphics, statistics, websites, etc...).

Furthermore, deductive reasoning, and inductive reasoning skills are problem-solving skills which are inevitable for learners to understand and use them to improve their learning performance, and become effective problemsolvers in a constantly changing world.

So, problem solving skills function as the sharpening tools, which foster learners' formal thinking skills. So, drawing valid conclusions from a set of premises (deductive reasoning) the conclusion is said to be deductively valid, whereas making inductive generalizations (an aspect of inductive reasoning) which are based on a set of observations, formulating and testing hypothesis, the conclusion is said to be reliable, and probable.

Accordingly, the researchers (the learners) are committed to find out supporting evidences, so as, either to reinforce, or reject the proposition (i.e. the hypothesis is considered the most important part of any scientific research).

For Cooper and Patton (2007) in inductive reasoning, the conclusion is always communicated with attentive probability that is the end result is not the end; another researcher may wish to handle the same research and verify the results (Inductive reasoning). So, based on sufficiently accepted set of evidences, and the statistical measurements, any conclusion is arrived at, is said to be probably true which means that the examiners may wish to check its significance and the results obtained are subject to future scientific investigation.

In the following discussion, more details on problem solving skills (deductive reasoning and inductive reasoning) will be provided.

\section{Reasoning, Thinking Skills and Learning}

Reasoning in Overtone's terms (1990) is described as "thinking that involves inferences, that is the process whereby one proposition (conclusion) is arrived and accepted on the basis of other propositions that were originally accepted" (Overtone, 1990:2).

Accordingly, reasoning is an aspect of thinking which entails a conscious mental activity which is directed toward investigating a kind of relationship between some thoughts to draw a conclusion(s) (Eisberg, 2001).

Simply take that based on the given premises, the conclusion, which is inferred is said to be necessarily valid (logical) or invalid in deductive reasoning, whereas in inductive reasoning, the conclusion is said reliable, (or unreliable) in inductive reasoning. 


\section{-Deductive Reasoning}

Deduction is concerned with drawing necessarily valid conclusions from a set of premises, not considering the truthfulness of information contained in the premises with respect to real life situations (Manktelow, 2012).

\section{Conditional Reasoning (C.R)}

Conditional reasoning (C.R) is an aspect of deductive reasoning. It is concerned with the relationship between conditions (premises)

For further clarification, we consider the following example:

$>$ If she feels happy, her eyes would be twinkling, and she would be smiling with joy.

$\checkmark$ So after checking some data concerning the woman being investigated (inductive reasoning), we stumble on the results mentioned below:

$>$ Her eyes are not twinkling, and she is not smiling with joy; therefore, she does not feel happy.

$\checkmark$ Obviously, the obtained result negates the aforesaid proposition, yet in deductive reasoning the structure of the proposition is what matters.

\section{Syllogism}

A syllogism is another kind of deductive reasoning, which consists of two main statements, which are assumed to be true, as well as, a conclusion. It involves quantifiers such as all, some, few etc... Quantifiers indicate a, quantity, amount and degree of a particular item (Maltin, 2003).

Consider a,b,c example :

a. Some countries are self-ruled. Note that somewhich is used at the very beginning of the statement is viewed as a quantifier which entails a group of countries (and not all of the countries) are independent whereas other countries may be under colonization.

b. Some self-ruled_countries_are re rich. the same rule applies for this statement but the adjective 'rich', that is a set of countries are rich whereas other are poor.

c. Therefore, some_countries_are rich. Given the above premises, a person may feel confused to deduce that some self-ruled countries are poor, yet she/he chooses 'rich' for it is available in the premise, and takes for granted a number of self-ruled countries as not wealthy, and may even think about other alternatives such as not all rich countries are self-ruled and so on.

Thus, the hallmark of deductive reasoning is that it helps learners to develop an ability to categorize information into a logically recognized whole.

\section{- Inductive Reasoning}

Inductive reasoning, the second type of problem-solving skills, starts with observing some sorts of repeatedly occurring instances pursued by making general inferences from them. Inferences which are drawn from observations 
are to be supported by the exploration of relevant and significant data (Cooper and Patton, 2007:191).

Determining cause and effect, formulating hypotheses, testing and experimenting, drawing analogies, and arriving at statistical generalization are some examples of inductive reasoning type of thinking. The conclusion drawn in inductive reasoning is probable, yet not necessarily absolute. That is to say, an investigator may wish to explore further (Cooper and Patton, 2007:190).

The advantage associated with handling inductive reasoning tasks, including guided discovery, and experimentation is to increase perception, and to understand of information, as well as, the joy of finding out things for the first time, which leads to construct a personally meaningful understanding of the world; an outcome which does not come from scratch and random guesses, but guided by scientific methods of inquiry, and evaluation.

\section{Cooperative Learning}

For Slavin (1995) "Cooperative learning refers to a variety of teaching methods in which students work in small groups to help one another learn academic content" (Slavin, 1995:2).

Accordingly, the definition of cooperative learning, which is cited above explains that cooperation entails all the participants (learners), being intentionally interacting within a cooperative learning setting to achieve a common goal(s).

However, the mutual interaction between learners toward the common goal is not considered unsystematic, or haphazard that is cooperative learning is purposefully designed, and structured with an aim(s) in mind, which is to orient learners toward enhancing their thinking skills, and cooperative skills simultaneously, within heterogeneous groups to learn and help their group mates learn as well. This leads learners to, eventually, get an idea of the importance of cooperation to achieve several goals, therefore get prepared to meet the complexity, and needs of the social organism (their society). This includes the future workplace.

\section{-Cognitive, Motivational and Social Explanations for Cooperative Learning}

\section{Cognitive Justification}

According to Slavin (1995) the extent to which learners process new learning experiences, increases in the presence of peers, or significant others. One justification is that learners, while cooperating to reach a common goal, discuss findings, and explore data from a variety of references are much more able at providing to each other considerably significant amount of contextual clues, which are thought to facilitate remembering, trigger questioning, and handle problem solving activities. In short, thinking is stimulated in the presence of others. Hence, varying teaching and learning methods, to mention few, hands-on, and inquiry-based 
learning are highly recommended to engage different types of thinking skills into a given task, and maintain increased motivation to learn (Slavin, 1995).

\section{Motivational Explanation}

Before explaining the motivational reasons, which make cooperative learning very appealing to use as a teaching, and learning method, some light is to be shed on the significance of motivation for learners (Further details on motivation; types and strategies are available in motivation section).

Motivation can be simply illustrated as the driving force, which draws learners toward the accomplishment of a goal, maintains focused attention, and allows the focus of learners' concentration on the target, and willingness to engage in lessons and learning activities a process, which outstandingly improves the intellectual devotion to the goal achievement (Brophy, 2004).

In Slavin's own words: "Motivation is what gets you going, keeps you going anddetermines where you are trying to go" (Slavin, 2006:317).

So, as far as cooperative learning is concerned, actually learning and thinking within heterogeneous groups turn into an immensely exceptional and exciting experience. This happens due to challenging learners to search for a solution for a given problem, constantly explain and analyze findings, and exchange opinions about relevant data all of which take place within groups.

From the beginning of the task, for cooperative learning to be highly effective, which is primarily designed to keep continued attempt to meet the challenge (problem solution), the active involvement into problem solving and learning is strongly emphasized. Hence, learners are active participants, rarely viewed indifferent to learning obstacles, and able to direct their learning, which mainly includes goal setting, planning, implementing, evaluating the results, and make sure that all the individuals contribute to the goal achievement.

As far as, learning environment is concerned Tang (1998:116) suggests that "cooperative learning provides a non-threatening learning context for interaction between students".

Thus, learners feel much more at ease, especially if they are expected to maintain attention on the learning experience, and repeatedly told to keep in mind the significance of cooperate to learn, and learn to cooperate, instead of worrying about the grades.

In addition, Slavin (2005) suggests that motivation increases because learners enjoy endless, and unlimited number of novel ideas, and opportunities to attend to real world situations. So, the classroom is 'the melting pot', where learners constantly meet to discuss results, and exchange opinions. Also, cooperative learning allows hands-on learning, which results in a fostered sense of responsibility for acting upon, and applying information, as well as, searching for tools to attain necessary data, which challenge previous understanding. Hence, learners, in Slavin's terms, "are exposed to alternative viewpoint that challenge initial understanding" (Slavin, 2005: 146). 
Furthermore, this exposition to different perspectives and thoughts from different participants raises learning achievement; learners constantly exchange, evaluate and provide peer feedbacks, a process which stimulates and exerts further mental work.

\section{Social Explanation}

When it is well-structured, cooperative learning leads to improved academic performance. Raising awareness of the importance of thinking skills for most of the human daily activities, leads learners to hold more responsibility for learning, and their thinking enhancement throughout learning.

One way to invite learners to think is to pose thought-provoking questions, where only few clues of the answers are deliberately provided. So, learners practice problem solving strategies, and are much more able at gaining a profound understanding of the given question or problem particularly when cooperative problem solving is repeatedly emphasized; they realize that there is a problem to solve (reflective thinking), then distinguish, as clearly as possible the obstacles, which prevent them to move toward the ultimate goal, which is problem solution.

Also, every learner actively contributes to the problem solution by suggesting a variety of possible alternatives (brainstorming technique is used) then and finally they try to choose the alternative, which is considered the most beneficial, that is the one which displays more gains and less losses (decision making). The success of their group depends on a successful cooperative problem-solving (cooperative learning requirement) with a purpose in mind (the goal) that all are to win, that is improve academic performance (an educational aim), and help that of others (otherwise fail). In brief, learners learn to swim together till they all reach the ultimately desired situation or sink together and restart again.

Interestingly, cooperative learning requires training learners to use a range of collaborative skills; for instance learning to sympathize, that is putting oneself in someone else's shoes. Also, learn to recognize each other's needs for assistance, providing encouragement and stating positive words.

Schunk (2009) explains that cooperative learning enhances in our learners the ability to collaborate to accomplish a task successfully.

The following list shows the most important constituents, which are claimed by Johnson and Johnson in their cooperative learning model and named as the elements of cooperative learning (Johnson and Johnson, 1981):

1-Positive interdependence; knowing that one's performance affects the success of the group mates, which leads to a considerable increase of effort.

2-Individual accountability

3-Promotive (face-to-face) interaction

4-Appropriate use of social skills (skills such as conflicts resolution, active listening, collaboration and team work skills) 
5-Group processing; group members constantly check the progress they made toward goal achievement.

\section{- Group Investigationto Foster Problem Solving Skills}

Group investigation is a type of cooperative learning , and teaching methods, which has its origin in the writings of the American educator, whose name was John Dewey (1970); a primary advocate of the establishment of thinking through democratic learning environment, where all learners have to engage common goal.

Group investigation is especially designed and recommended to direct learners toward getting them involved into problem solving tasks to foster various aspects of thinking through a methodological research, which calls for observation, questioning, and investigation, as well as, collaborative skills in the classroom such as turn taking and expressing concerns and empathy.

Due to its promising positive effect on the enhancement of problem solving skills, group investigation is an influential learning and teaching method to ensure higher motivation, and commitment to the common objective. Also, as far as genuine interaction with available research tools is concerned, group investigation allows learners to be equipped with necessary research tools, which activate thinking and facilitate goal attainment, and communication skills while investigating the research topic (Slavin,1985).

The product is valued with regard to the higher level thinking, which is reflected by the significance of the research being conducted, as well as, the strategies used to collect and distinguish relevant data, and the credibility of the references, which are relied on during the investigation (Slavin, 1995).

Moreover, the affective experience is also evaluated, that is learners' motivation to persist, and devote sufficient time, and hard work to complete the investigation. (Slavin, 1995)

\section{Motivation}

Based on a wide investigation of motivation, we have encountered a plethora of definitions from different perspectives; we wish to focus on the cognitive and social views which unveil the importance of motivation for improving learning and making learning experiences meaningful.

So, for what is meant by learners having increased motivation or otherwise to learn, Brophy (2004:4) suggests a specific definition of the concept of student motivation. In his own words:"student motivation is used to explain the degree to which learners invest attention and effort in the various pursuits" (Brophy, 2004:4).

Motivation is described as the energy which fuels forward one's desire to achieve and succeed. Thus, learners are not expected to attend to a particular issue if they lack enough conviction and motivation to do so, that is to say, necessary motives which captivate their attention to the given task. Convictions, which involve the perceived value of the task, which means that 
the learner is intrinsically motivated to handle the task, and commit to it as well, or from a wholly different perspective, the learner is extrinsically motivated, that is she may wish to realize a social approval, and acceptance by a successful accomplishment of the task. As a matter of fact effective learners possess a combination of intrinsic, as well as extrinsic reasons or motives to cling to the task accomplishment (Williams and Burden, 1997).

In the following, we shed light on few teaching technique which increase sustained attention and boost effort exertion which are mainly oriented toward enhancing learning and thinking skills.

-The role played by emotions to raise and keep learners highly motivated is acknowledged by many educators. The focal point here, is that the classroom instructions are to be presented carefully with respect to learners' interest and a personally meaningful way the learners view the world.

Also, it is worth saying that learning, including English language learning, is deemed an emotional experience which affects learners' motivation and attitudes, as well as a cognitive experience, where a set of mental processes(such as memory, and reasoning) are activated to act upon new information. This suggests that the learners can be trained to take the advantage from a variety of learning strategies , and to interact with $21^{\text {st }}$ century technology which are arranged to meet their cognitive and affective needs to mention few, web surfing, social networks both of which allow instant interaction with information group discussion, cooperation and hands-on learning, as well as the indispensable role played by the learning environment which includes the teachers' behavior in the classroom for learners can largely be influenced by the teachers' beliefs and expectations feedback, positive statement such as words of praise(Williams and Burden,1997).

-Challenging learners with the thought-provoking, yet not very hard or unobtainable tasks. A challenging situation in its own right is a motivation that orients learners toward investigating and exploring operations which lead to overcome possibly occurring obstacles. Challenging tasks push learners to acquire several learning and thinking skills, such as goal setting, planning and carrying out the plan, evaluating the end result, reviewing and modifying the product. However it is worth mentioning that the task given to the learners to deal with should be neither unattainable so learners may feel overwhelmed and lose confidence in their ability to stick with the task, nor easy to grasp, vain and purposeless for learners would not exert genuine effort and learn less. In fact, during both situations the learners are likely to fail to recognize their own potentials, and enjoy learning experiences.

- Strategies for assessment. Providing feedbacks is the most effective assessment strategy for boosting learners' motivation to learn, and thereby enhancing their academic performance. Feedbacks are perceived as teachers' ways of telling learners what they can do to modify their learning performance. 
Group discussion involves both learners and teachers in a topic of interest would facilitate the evaluation of the performance, and allows relaxed learning environment. Question-response and performance assessment are also assessment tools used to boost higher motivation and evaluate the improvement of the academic performance (Sinagatullin, 2009).

-Another key principle which is drawn from social Constructivism emphasizes the dynamic interaction between the teacher, the learner and the task that is the mutual endeavor to complete the task. (Williams \& Burden, 1997) The mutual interaction to solve a problem allows a flexible exchange of experiences, as well as, the employment of possibly available learning skills learners bring to the classroom, a process, which shows increased motivation to learn due to the relaxed, and dynamic learning environment. Also, and most interestingly, the mutual exchange of data and previous learning experiences allow more exposure to analogous cases, which share common patterns to help dealing with the given task that is problem solving via analogy. This approach to problem solving facilitates understanding of the given situation or problem and fosters long-term retention of data.

The learning environment within which problem solving activities are being practiced, the availability of learning tools, the teachers' beliefs, and expectations of their learners, influence learners' engagement into the tasks, and actually tell lot of things about the effectiveness of the instruction being communicated to the learners.

\section{The Experimental Design:}

In this papers, we present data which we collected through classroom observation and testing. Pre-test and post-test were administered to see the effects of exposing learners to the training program on their ability to solve problems within groups, and increase motivation. The training program consists of a variety of activities, such as thought- provoking activities, which are mainly concerned with real life issues; we made sure that the activities are as relevant and interesting as to the learners' studies in order to maintain interest and concentration. The subjects of our sample study geology, a science which is concerned with earth different features and changes; this includes climate shift. Also, to build cooperative teams, we have organized team building activities such as the helium roll, and survival scenarios which require learners to work together in order to succeed.

Throughout the administration of the activities, we have emphasized three main requirements, these are, questioning, investigation, hands-on learning, and communication.

Also, it is worth saying that our learners learn to solve problems while practicing problem solving strategies. Being asked to handle an issue which is relevant to real world, our participants are asked (1)to identify the problem, 
preferably restating what the problem is,(2) generating possible solutions( brainstorming technique ),(3) looking back at the suggested solution, and evaluating groups 'product. For instance, in a rainy day, our learners are told the following:

\section{* Temperatureincreasesafter rain, Explain!}

Breaking the sentence into its components, the learners start their quest by visualizing the situation, asking WH questions, investigate causes and effects, and then they look for reasonable answers through observing instances, testing and gathering data, and comparing their answers with that of relevant references and scientific research.

\section{* Survival scenarios}

Learners were told the following situation:

"You are in the classroom, and suddenly you felt that the ground is moving. Alas, an earthquake of 5.7 degrees according to JMA scale (Japan Meteorological Agency seismic intensity scale) is shaking the area. Your classmates and you have to act swiftly to prevent possible damages and to survive..."

Once again, the learners visualize the situation, and brainstorm many possible safety tips.

Active involvement into problem solving tasks and other cooperative learning activities is repeatedly emphasized while instruction, however we noticed few, though not severe and overwhelming irresponsibility from learners' part ; actually some learners were not completely committed to doing their share of the work, instead they were noticed to rely on their group mates to do the entire task.

In this research, the paired t.test is applied because it is strongly recommended by psychologists and statisticians such as Miller (1984), for it is considered applicable and reasonably used to compare a sample group's scores before, and after the intervention. That is how different the participants performed in both situations, as to indentify the significance (or insignificance) of the treatment they have been receiving during three months of time. In our case, the intervention is presented in the form of the training program, which is particularly designed to actively involve learners into problem solving activities, and cooperative learning. So, learners are not allowed to be passive recipients of knowledge during the learning process, for they are made aware of, first, the introduction of the training program as a teaching and learning method to get them involved into problem solving, as well as push them to hold more responsibility for learning and thinking enhancement, and second, cooperative learning is introduced being the basic ground on which to build life-long skills, such as collaborative skills to construct their own understanding of real world issues, and to work toward a common goal. 
In this research we suggest that cooperative learning has a positive effect on the improvement of learners' performance, and can better direct learners to focus on triggering thinking, where the task requires cooperativeness, as well as problem solving skills for its fulfillment. Also, increased motivation is observed through learners ability to enjoy research and group communication, all of which due to a relaxed, yet dynamic learning environment, which calls for cooperative learning, thinking, and discovery. We hypothesized the following: enhancing problem solving skills, and motivation through cooperative learning.

This research is guided by four main questions we attempted to answer during and after the conduction of training program. They are listed in the following:

First, can deductive and inductive reasoning skills be promoted through an educational program of three months duration?

Second, is it possible to stimulate learners both intrinsic and extrinsic motivation via cooperative learning and teaching approach?

Third, can we assume that enhancing learners' capacity to think deductively and inductively boost their motivation to apply problem solving skills as essentially led by the banner 'knowledge boosts confidence'?

Fourth, can learners be trained to adopt group investigation as a learning method to uncover and understand the world?

\subsection{Sampling}

The sample of 20 participants from a population which contains sixty six students, who are enrolled in the faculty of the Science of the Earth, preparing for the Master grade is selected randomly for the purpose of the present study. Due to the varied previously experienced learning situations, we could hold high expectations for postgraduate students' willingness to engage in problemsolving activities, which are selected to be relevant to their field of study, and which pose before them a problem to solve, as well as to serve the present research aim.

Cooperative learning is introduced to enhance problem solving skills, and increase motivation. Though it is highly appealing, some learners have difficulty coping with cooperative learning, believing that it more demanding than the traditional method of instruction, whereas some have welcomed it, thinking it would meet their need to engage into hands-on activities. This could mainly be explained by the individual differences, which states that learners come from various backgrounds which lead to differences in learning styles. However, exposing learners to positive results, which are brought by cooperative learning, help learners to be better inclined to adopt cooperative learning as a learning method that contributes to a noticeable thinking and learning improvement. 
In addition, problem solving skills are considered a problem to handle that is learners are challenged with thought provoking problems, which make them attempt to explore and foster their problem solving ability, and potential skills they already possess.

\subsection{Issues to Training Program}

A training program was designed to engage learners into problem solving activities which lead them to exercise and reflect on questions or problem for themselves, therefore, they are pushed to explore and experiment various learning references, in order to end up with their own understanding of the present learning experiences.

Furthermore, our learners are equipped with a set of probing questions they ask every then and now to check their understanding of the given problem, to keep track on the main task, and to allow a maintained attention on the task progress and accomplishment. This includes the problem identification (what is the problem?), the research tools (what are the available research tools which aid problem solution?), the causes behind the problem (what causes the present problem?), and the possible solution (what is the best possible solution?). The paired t.test was conducted to see the difference between scores obtained before and after the conduction of the training program to check the influence of the training program, and its significance to learners' learning and academic performance.

(1)The table below shows the complied scores which are obtained before and after the training program

\begin{tabular}{|c|c|c|c|c|}
\hline $\begin{array}{l}\text { SUBJECT } \\
\text { S }\end{array}$ & $\begin{array}{l}\text { SCORES } \\
\text { BEFORE } \\
\text { TREATMEN } \\
\text { T }\end{array}$ & $\begin{array}{l}\text { SCORES } \\
\text { AFTER } \\
\text { TREATMNE } \\
\text { T }\end{array}$ & $\begin{array}{l}\text { DEFFERENC } \\
\text { E d (the } \\
\text { difference } \\
\text { between pre- } \\
\text { test and post- } \\
\text { test scores) }\end{array}$ & $\begin{array}{l}\text { the } \\
\text { differenc } \\
\text { e d }^{2}\end{array}$ \\
\hline 1 & 11 & 15 & 04 & 16 \\
\hline
\end{tabular}


Debache Ahlam

\begin{tabular}{|c|c|c|c|c|}
\hline 2 & 04 & 09 & 05 & 25 \\
\hline 3 & 15 & 16 & 01 & 01 \\
\hline 4 & 02 & 06 & 04 & 16 \\
\hline 5 & 02 & $\mathbf{0 3}$ & 01 & 01 \\
\hline 6 & 01 & 05 & 04 & 16 \\
\hline 7 & 07 & 11 & 04 & 16 \\
\hline 8 & 08 & 05 & -3 & 09 \\
\hline 9 & $\mathbf{0 3}$ & 06 & $\mathbf{0 3}$ & 09 \\
\hline 10 & 10 & 11 & 01 & 01 \\
\hline 11 & 02 & 05 & $\mathbf{0 3}$ & 09 \\
\hline 12 & 07 & 09 & 02 & 04 \\
\hline 13 & 02 & 10 & 08 & 64 \\
\hline 14 & 13 & 15 & 02 & 04 \\
\hline 15 & 02 & 02 & $\mathbf{0}$ & 0 \\
\hline 16 & 12 & 14 & 02 & 04 \\
\hline 17 & 11 & 12 & 01 & 01 \\
\hline 18 & $\mathbf{0 3}$ & 11 & 08 & 64 \\
\hline 19 & 17 & 17 & $\mathbf{0}$ & 0 \\
\hline 20 & 11 & 13 & 02 & 04 \\
\hline
\end{tabular}


(2) Table below shows two measures of the same subjects, pre.test and post.test which are followed during the training program.

\begin{tabular}{|c|c|c|c|}
\hline $\begin{array}{c}\text { Mean for } \\
\text { scores before } \\
\text { T.P }\end{array}$ & $\begin{array}{c}\text { Means for } \\
\text { scores after T.P }\end{array}$ & $\begin{array}{c}\text { The sum of } \\
\text { difference in } \\
\text { two conditions }\end{array}$ & $\begin{array}{c}\text { The sum of } \\
\text { difference } \\
\text { multiplied by the } \\
\text { difference d }\end{array}$ \\
\hline $\mathbf{M 1}=8.25$ & $\mathbf{M} 2=9.75$ & $\sum \mathbf{d}=\mathbf{5 2}$ & $\sum \mathbf{d 2}=\mathbf{2 6 4}$ \\
\hline
\end{tabular}

Table (2) shows a significant difference between the mean for scores before and after taking the training program. So, we deduce that training program which is essentially designed to involve learners into problem solving activities and cooperative activities brought about a difference between earlier performance and later performance as shown by the result.

Figure(1)

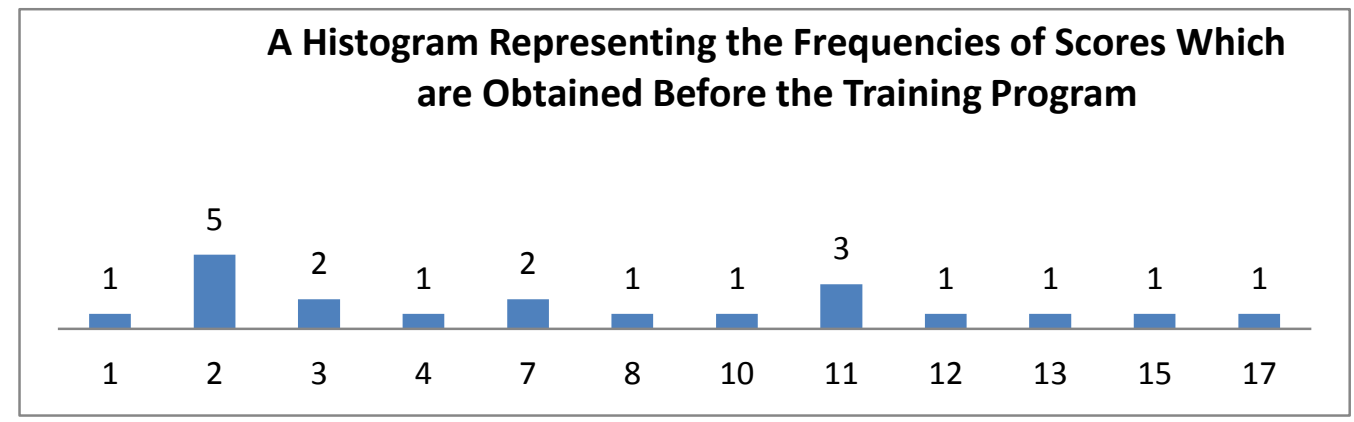

The vertical axis shows the data obtained before the training program. Above each bar in the histogram we see the number of frequencies of each score 
Figure(2)

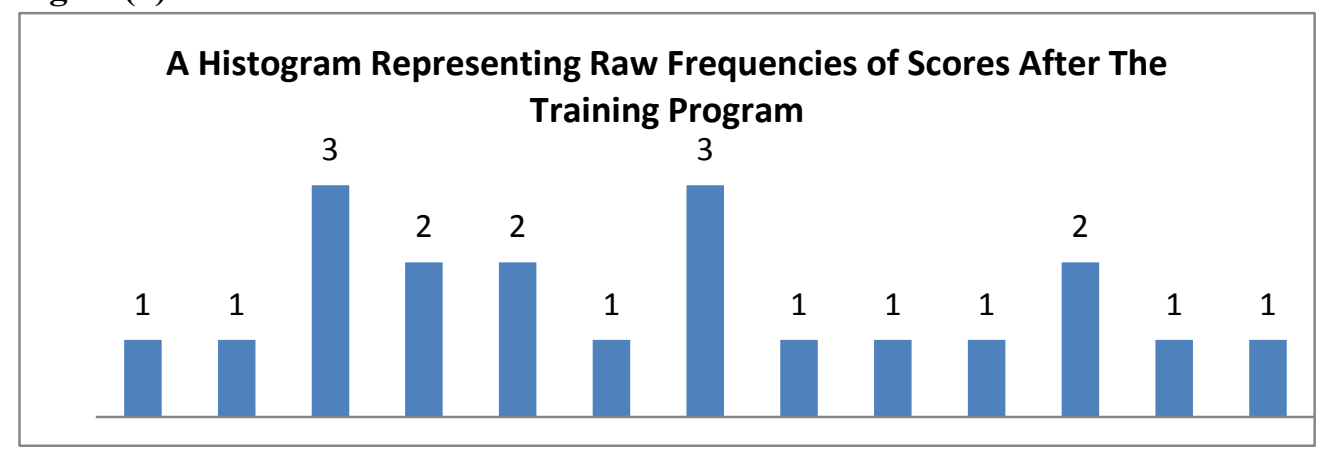

The vertical axis presents the obtained scores after the training program, and the frequency distribution is shown on top of every bar

The t.obtained we calculated for the difference between the scores mean of pre.test and the scores mean of post.test is 4.47 , which is obviously more extreme than the critical value for $t$ which is 2.09 as found in the distribution table namely $4.47>2.09$. The result indicates that the difference between the scores mean of pr.test and the scores mean obtained on the post.test did not probably occur by chance.

(1) The table below displays the difference between the $t$ obtained and the critical value for $t$

\begin{tabular}{|c|c|c|c|c|}
\hline $\begin{array}{l}\text { Degree } \\
\text { freedom }\end{array}$ & $\begin{array}{ll}\text { The SUM OF THE } \\
\text { DIFFERENCES (1) } \\
\text { BETWEEN THE } \\
\text { SCORES } \\
\text { OBTAINED } \\
\text { BEFORE AND } \\
\text { AFTER } & \\
\text { TRAINING } & \\
\text { PROGRAM } & \end{array}$ & $\begin{array}{ll}\text { The SUM OF } & \text { THE } \\
\text { DIFFERENCES } & \text { (2) } \\
\text { BETWEEN THE } & \text { THE } \\
\text { SCORES } & \\
\text { OBTAINED } & \\
\text { BEFORE } & \text { AND } \\
\text { AFTER } & \text { THE } \\
\text { TRAINING } & \\
\text { PROGRAM } & \end{array}$ & $\begin{array}{l}\text { The } t \\
\text { obtained from } \\
\text { the scores } \\
\text { mean of pre } \\
\text { test and post } \\
\text { test }\end{array}$ & $\begin{array}{l}\text { The critical } \\
\text { value for } t\end{array}$ \\
\hline df & $\Sigma \mathbf{d}$ & $\Sigma \mathrm{d} 2$ & t.test & t.critical \\
\hline 19 & 52 & 264 & 4.47 & 2.09 \\
\hline
\end{tabular}


The t.obtained we calculated for the difference between the scores mean of pre.test and the scores mean of post.test is 4.47 , which is obviously more extreme than the critical value for $t$ which is 2.09 as found in the distribution table namely $4.47 \geq 2.09$. The results indicate that the difference between the scores mean of pre.test and the scores mean obtained in the post.test did not probably occur by chance.

The required value of $t$ at 0.05 level of significance for $19 d f$ is 2.09; since the obtained value of $t$ is higher than the $t$ critical value (the obtained value of $t$ is much higher than the required value), we can say then that the training program has a positive influence on the performance of learners.

\section{Conclusion}

From this article, we can deduce that to tell learning is effectively achieved implies learners making sense of the given task or activity. For this purpose, we attempt to aid learners to construct their own understanding of different learning experiences through exploration and hands-on learning. As a result, learners are to concentrate not only on obtaining higher grades yet and for the most important affair to handle is the need to gain knowledge, and use it when required. Knowledge is regarded nonsense and useless when it is merely stored in memory, yet bringing it to light as a mean at the to solve a problem, understand a situation or event, and be an assistance to improve life conditions which is mainly emphasized through the active involvement into problem solving situations and cooperativeness in order to meet a common goal and which are interestingly considered and required by the $21^{\text {st }}$ century education which put emphasis on the enhancement of cognition, motivation and cooperativeness.

\section{Bibliography}

(1)-Anderman,E.M.,Anderman,L.H.,(2009)"Psychology of Classroom

Learning". Macmillan Reference USA

(2)-Baddeley A, D., (1997)"Human Memory: Theory and Practice".

Psychology press

(3) Brophy

(4)-Cooper,S.,Patton,R.,(2007)”Writing Logically, Thinking Critically».

Pearson Longman

(5)Eisberg

(6)-Gillies,R.m.,Ashman,A.F. ,(2003)"Cooperative Learning: The Social and Intellectual Outcome of Learning".Routledge

(7)-Manktelow,K.I.,(2012)"Thinking and Reasoning». Psychology Press

(8)-Matlin,M.W.,(2003)"Cognition”.(fifth ed).John Wiley and sons,Inc.

(9)-Millis,J,B.,(2002)"Enhancing Learning and More-Through Cooperative

Learning".retreived November 12,2013,from http://www.theideacenter.org 
(10)-Moseley,D.,(2005)'Frameworks For Thinking A Handbook for Teaching and Learning".Combridge University Press

(11)-Olson,M.H.,Hergenhahn,B.R.,(2009)"An Introduction To Theories Of Learning".(Eighth ed)Pearson Education,Inc.

(12)-Overton,W.F.,(1990)"Reasoning, Necessity and Logic: Developmental perspectives". Routledge Taylor\&Francis Group

(13)-Schunk,D.H.,(2009)"Learning theories An Educational Perspective".(Fifth ed).Pearson Education,Inc.

(14)-Sinagatullin, I.M., (2009)" Teaching is More Than a Pedagogical Practice: Thirty Three Strategies for Dealing with Contemporary Student". Rowman and Littlefield Education

(15)-Slavin,R. E.,(1995) “Cooperative Learning: Theory and Practice”.(Second ed).library of Congress Cataloging-in-Publication Data

(16)-Tang,C.(1998) "Effects of Collaborative Learning on the Quality of Assignment. In B.Dart\&Boulton- Lewis (Eds.)

(17)-Williams,M.,Burden,R.L.,(1997)"Psychology for Language Teachers: a Social Constructivist Approach".Combridge University Press 